\title{
Quality and antioxidant properties of jelly incorporated with corn concentrate
}

\author{
Min Ji Cha, Jun Ho Lee* \\ Department of Food Engineering, Daegu University, Gyeongsan 38453, Korea
}

\begin{abstract}
Gummy jellies are popular desserts or snacks and widely consumed by various age groups around the world. Consumers' new needs and desire for a healthy food have promoted supplementation of the functional food ingredient to snack foods. As com concentrate (CC) possesses diverse functional activities, it may be beneficial to increase its consumption via supplementation into snack foods such as jelly. There has been a scarcity of reports on antioxidant potential of $\mathrm{CC}$ and how much level is enhanced which occurs upon making $\mathrm{CC}$ incorporated jellies. This prompted us to undertake the present investigation with the objective to evaluate the physical, sensory, and antioxidant characteristics of jellies containing various levels of $\mathrm{CC}(3 \%, 6 \%, 9 \%$, and $12 \%)$. The $\mathrm{pH}$ level (6.98 to 6.45), moisture content $\left(89.34\right.$ to $80.06 \%$, w.b.), and lightness $\left(L^{*}\right)(20.79$ to 16.50$)$ decreased significantly while total soluble solids $(1.04$ to $2.48{ }^{\circ}$ Brix), hardness $(3.47$ to $5.57 \mathrm{~N})$, redness $\left(a^{*}\right)(-0.45$ to 4.95$)$, and yellowness $\left(b^{*}\right)(4.76$ to 7.70$)$ increased significantly with increasing levels of added $\mathrm{CC}(\mathrm{p}<0.05)$. In addition, 2,2-diphenyl-1-picrylhydrazyl $(0.62$ to $3.45 \%)$ and 2,2'-azino-bis-3-ethylbenzthiazoline-6-sulphonic acid (0.22 to $1.88 \%$ ) radical scavenging activities significantly increased $(\mathbf{p}<0.05)$, and they were well-correlated. Consumer acceptance test indicated that addition of $6 \% \mathrm{CC}$ had a favorable effect on consumer preferences for most attributes. Based on our study, jelly with $6 \% \mathrm{CC}$ is recommended for developing CC-added jellies with improved overall qualities without sacrificing consumer acceptability while taking advantage of the functional properties of $\mathbf{C C}$.
\end{abstract}

Key words : corn concentrate, jelly, physicochemical properties, consumer acceptance, antioxidant properties

\section{Introduction}

Gummy jellies are popular and widely consumed by various age groups as a dessert or snack. They are made from concentrated sugar solutions, gelling agents, and other minor ingredients (coloring, acid, and flavoring agents) (1). The raw material is first gelatinized by heating and mixing with acids, coloring, and flavoring, after which the molten product is formed in molds of different sizes and shapes (2). Gelatin and modified starch are extensively used to produce the gels with firm structures while also being soft and chewy (1).

Corn is one of the most produced crops in the world along with rice and wheat (3). Corn contains an abundance of

*Corresponding author. E-mail : leejun@daegu.ac.kr

Phone : 82-53-850-6531, Fax : 82-53-850-6539

Received 16 July 2018; Revised 17 July 2018; Accepted 20 July 2018.

Copyright (c) The Korean Society of Food Preservation. All rights reserved. phenolics, which have been reported to have antiinflammatory, anti-diabetic, anti-obesity, antioxidant, and anti-cancerous properties (3). The development of products as functional foods enriched with ingredients such as corn concentrate (CC) could increase consumer awareness about health as well as overall product value. $\mathrm{CC}$ has been widely used in the preparation of beverages (juices and drinks), biscuits, candies, jellies, and so on.

A literature review indicated that various concentrates such as black ginseng concentrate (4), black garlic concentrate (5), Gastrodia elate concentrate (6), Rehmannia radix concentrate (7), purple sweet potato concentrate (8), jujube concentrate (9), and cranberry concentrate (10) have been successfully used in jelly manufacturing. Nevertheless, little information is available regarding the effects of $\mathrm{CC}$ on the physicochemical and sensory properties of gummy jellies.

In this study, CC was supplemented with water in order to improve its functional and nutritional value. The aim of this research was to determine the effects of CC substitution 
(3-12\%) on the physical and sensory characteristics of jellies. The antioxidant properties of CC-supplemented jellies were also determined.

\section{Materials and methods}

\section{Jelly materials}

Corn concentrate (CC) (Sunin Co., Chungnam, Korea), gelatin (Samwon, Daegu, Korea), and sugar (CJ, Seoul, Korea) were of commercial grade and were purchased in a local market. The relevant characteristics of CC were as follows: $\mathrm{pH} 5.89$, soluble solids content $6.8{ }^{\circ} \mathrm{Brix}$, and $\mathrm{L}^{*}$, $\mathrm{a}^{*}$, and $\mathrm{b}^{*}$ values were $35.90,7.37$, and 2.48 , respectively. This commercial CC contained white sugar, starch syrup, CC paste, purified water and salt, flavoring agents, emulsifier, and sodium alginate. All ingredients are generally recognized as safe (GRAS).

\section{Preparation of jellies}

The final CC concentration (up to $12 \%$ ) was determined by several preliminary studies. The jellies were prepared by mixing water, sugar, gelatin, and an appropriate amount of $\mathrm{CC}$ : $0,12,24,36$, and $48 \mathrm{~g}$ of $\mathrm{CC}$ was replaced with water depending on the concentration, respectively. First, sugar (30 g) was dissolved in boiling water $(200 \mathrm{~mL})$ for $4 \mathrm{~min}$ and $200 \mathrm{~mL}$ of water with dissolved gelatin for $2 \mathrm{~min}$, after which an appropriate amount of $\mathrm{CC}$ was mixed. The final mixture was covered and boiled for $4 \mathrm{~min}$. The mixture was then poured immediately into molds and left for $30 \mathrm{~min}$ at room temperature, after which samples were refrigerated at $4{ }^{\circ} \mathrm{C}$ for $3 \mathrm{~h}$ before the experiments. The samples were warmed at room temperature before each analysis. The standard jellies recipe consisted of $400 \mathrm{~mL}$ (100\%) of water (without CC served as a control), $30 \mathrm{~g}$ of white granulated sugar, and $10 \mathrm{~g}$ of gelatin.

\section{Physical analysis}

Ten grams of sample mixed with $90 \mathrm{~mL}$ of distilled water was prepared to measure the $\mathrm{pH}$ levels of jelly samples with a pH meter (MP230, Mettler Toledo, Schwerzenbach, Switzerland) at room temperature. The same samples were used to determine total soluble solids (TSS), expressed in ${ }^{\circ}$ Brix, using an Atago refractometer (PR-201, Atago Co., Ltd., Tokyo, Japan). Moisture content was determined by drying pre-weighed amounts of samples to a constant weight at $105^{\circ} \mathrm{C}$ in an oven for $24 \mathrm{~h}$. All measurements were carried out five times, and mean values were compared.

Color was measured in terms of $\mathrm{L}^{*}, \mathrm{a}^{*}$, and $\mathrm{b}^{*} \mathrm{CIE}$ values using a Minolta Spectrophotometer (CM-600d, Minolta Co., Osaka, Japan) equipped with a D65 standard illuminant, an $8 \mathrm{~mm}$ aperture, and a $10^{\circ}$ standard observer. The spectrophotometer was calibrated with a standard white calibration cap supplied by the manufacturer. Color values were recorded as $L^{*}, a^{*}$, and $b^{*}$ values. $L^{*}$ value represents lightness $\left(0=\right.$ black, $100=$ white), $a^{*}$ value represents the red $(+)$ to green (-) axis, and $b^{*}$ value represents the yellow (+) to blue (-) axis. Color was measured at the same location ( ix sides of each cube) using five jelly cubes $(3 \times 3 \times 3 \mathrm{~cm})$ for each treatment. Textural characteristics were evaluated by $30 \%$ compression of individual samples $(3 \times 3 \times 3 \mathrm{~cm})$ with a computer-controlled Advanced Universal Testing System (LRXPlus, Lloyd Instrument Limited, Fareham, Hampshire, $\mathrm{UK}$ ) at room temperature with a $5 \mathrm{~cm}$ diameter stainless steel disc probe. The crosshead speed was $1 \mathrm{~mm} / \mathrm{s}$. Twenty samples for each replication were tested, and their mean values were compared.

\section{Antioxidant analysis}

The DPPH radical scavenging activities of the samples were measured in terms of their hydrogen-donating or DPPH radical scavenging activity. The assay was performed as previously described by Brand-Williams et al. (11) with some modifications. Briefly, $0.2 \mathrm{mM}$ solution of $\mathrm{DPPH} \cdot$ radical in ethanol was prepared, after which $5 \mathrm{~mL}$ of this solution was added to $1 \mathrm{~mL}$ of sample solution in ethanol at different concentrations. The solution was then shaken and left to stand for $10 \mathrm{~min}$. Decolorization of DPPH-donated protons was determined by measuring the absorbance at $517 \mathrm{~nm}$ using a spectrophotometer (Optizen 2020 UV Plus, Mecasys Co., Ltd., Daejeon, Korea). DPPH radical scavenging activity was calculated using the following equation:

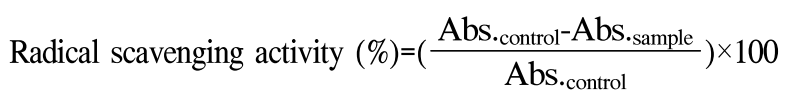

Spectrophotometric analysis of $\mathrm{ABTS}^{+} \cdot$ radical scavenging activity was carried out according to the method used by Re et al. (12) with slight modifications. The assay is based on the ability of antioxidants to reduce $\mathrm{ABTS}^{+}$. (blue/green) for the generation of $\mathrm{ABTS}^{-2}$ (colorless). $\mathrm{ABTS}^{+}$. cation radical was produced by a reaction between $7.4 \mathrm{mM}$ ABTS in $\mathrm{H}_{2} \mathrm{O}$ and $2.6 \mathrm{mM}$ potassium persulfate during storage in the dark at room temperature for 12-16 h. Before use, $\mathrm{ABTS}^{+}$. 
solution was diluted with methanol to obtain an absorbance of $1.1 \pm 0.02$ at $734 \mathrm{~nm}$. Subsequently, $3 \mathrm{~mL}$ of $\mathrm{ABTS}^{+}$. solution was added to $0.1 \mathrm{~mL}$ of sample. After $10 \mathrm{~min}$, percent inhibition at $734 \mathrm{~nm}$ was calculated for each concentration relative to blank absorbance.

\section{Sensory analysis}

$\mathrm{CC}$ jellies were evaluated by 50 consumer panelists. Five samples were presented in random order, and they were asked to evaluate consumer attributes of color, flavor, taste, texture, and overall acceptability. Consumer participants were asked to evaluate preference levels using a nine-point hedonic scale (9=like extremely, 5=neither like nor dislike, and $1=$ dislike extremely). Each sample $(3 \times 3 \times 3 \mathrm{~cm})$, randomly coded using a three-digit number was evaluated in each session. Consumers received a tray containing the samples, a glass of water, and an evaluation sheet. Participants were advised to rinse their palates between samples to minimize residual flavor effects. Enough space was given to handle the samples and questionnaire, and evaluation time was not constrained. No specific compensation was given to the participants.

This study was approved by the Daegu University Institutional Review Board (IRB\# 1040621-201711-HR-017002).

\section{Statistical analysis}

Statistical analysis was carried out using the SAS for Windows version 9.1 (SAS Inst. Inc., Cary, NC, USA). Results were expressed as mean values with the corresponding standard deviation, and significant differences were compared with Duncan's multiple range test at a 5\% level of significance.

\section{Results and discussion}

\section{Physical characteristics}

Table 1 describes the physical characterization of the jellies supplemented with different levels of corn concentrate (CC). The $\mathrm{pH}$ values assessed in jellies ranged from 6.45 to 6.98 and decreased upon addition of an increasing amount of $\mathrm{CC}$ $(p<0.05)$. Nevertheless, only minor changes were observed. Similar reduction of $\mathrm{pH}$ was observed among jellies incorporated with black garlic concentrate (5) and jujube concentrate (9), probably due to the weak acidic nature of the supplemented concentrate.

Moisture contents of samples ranged from 80.06 to $89.34 \%$ (w.b.), and the control sample exhibited the highest moisture content. This range is in good accordance with the values for jellies incorporated with purple sweet potato concentrate (82.03-83.82\%) (8) and jujube concentrate (79.56-84.35\%) (9). A similar trend has also been reported for jellies supplemented with jujube concentrate (9). Other studies have reported slightly lower ranges of moisture content due to the formulation of ingredients and additives. Moisture contents ranged from $65.22-74.81 \%$ and $59.37-62.23 \%$ for jellies incorporated with Gastrodia elata concentrate (6) and Rehmannia radix concentrate (7), respectively. Total Soluble solids (TSS) increased significantly with increasing CC concentration $(p<0.05)$. This result is probably attributable to the addition of soluble solids from $\mathrm{CC}$, which showed a TSS of $6.8{ }^{\circ}$ Brix. Similar results were reported for jellies supplemented with black ginseng concentrate (4) and jujube concentrate (9).

Texture analysis found that the hardness of jellies increased significantly as the $\mathrm{CC}$ concentration increased $(\mathrm{p}<0.05)$. Increased levels of $\mathrm{CC}$ remarkably increased the hardness of jellies ranging from $3.47 \mathrm{~N}$ at $0 \%$ replacement to 5.57 $\mathrm{N}$ at $12 \%$ replacement. The higher hardness of jellies containing a higher amount of $\mathrm{CC}$ could be attributed to lower water holding capacity (8) as well as moisture content. A similar result was reported for jellies incorporated with black ginseng concentrate (4) and purple sweet potato concentrate (8).

Together with texture, surface color is a very important element determining initial acceptability in consumers. Jellies made with $\mathrm{CC}$ showed significantly different surface color values compared to the control $(\mathrm{p}<0.05)$. $\mathrm{L}^{*}$ values decreased significantly with an increasing amount of $C C(p<0.05)$. On the other hand, $\mathrm{a}^{*}$ and $\mathrm{b}^{*}$ values showed reverse trends, but no significant differences in $a^{*}$ values were detected among the $9-12 \%$ samples or in $b^{*}$ values among the 3-9\% samples. As the concentration of $\mathrm{CC}$ in the formulation increased, jellies became darker and more reddish and yellowish (Fig. 1). These results are in accordance with the findings reported for jellies supplemented with purple sweet potato concentrate (8). These results suggest that the color of jellies can be easily controlled based on the concentration of $\mathrm{CC}$ according to consumer and/or manufacturer preferences.

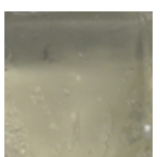

Control

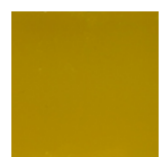

$3 \%$

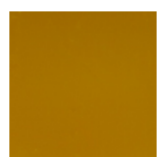

$6 \%$

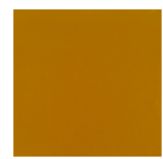

$9 \%$

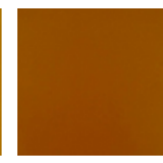

$12 \%$
Fig. 1. Appearance of jellies with different levels of corn concentrate. 
Table 1. Physical properties of jelly incorporated with different levels of corn concentrate

\begin{tabular}{|c|c|c|c|c|c|c|}
\hline \multirow{2}{*}{\multicolumn{2}{|c|}{ Property }} & \multicolumn{5}{|c|}{ Corn concentrate $(\%)$} \\
\hline & & 0 & 3 & 6 & 9 & 12 \\
\hline \multicolumn{2}{|c|}{$\mathrm{pH}$} & $6.98 \pm 0.12^{\mathrm{al})}$ & $6.90 \pm 0.03^{\mathrm{ab}}$ & $6.79 \pm 0.19^{b}$ & $6.54 \pm 0.08^{c}$ & $6.45 \pm 0.08^{c}$ \\
\hline \multicolumn{2}{|c|}{ Moisture content (\%) } & $89.34 \pm 0.14^{\mathrm{a}}$ & $87.10 \pm 0.12^{b}$ & $84.26 \pm 0.05^{c}$ & $82.01 \pm 0.13^{\mathrm{d}}$ & $80.06 \pm 0.11^{\mathrm{e}}$ \\
\hline \multicolumn{2}{|c|}{ TSS $\left({ }^{\circ}\right.$ Brix $)$} & $1.04 \pm 0.05^{\mathrm{e}}$ & $1.26 \pm 0.05^{\mathrm{d}}$ & $1.42 \pm 0.04^{\mathrm{c}}$ & $1.60 \pm 0.00^{\mathrm{b}}$ & $2.48 \pm 0.04^{a}$ \\
\hline \multicolumn{2}{|c|}{ Hardness $(\mathrm{N})$} & $3.47 \pm 0.29^{\mathrm{d}}$ & $3.72 \pm 0.58^{\mathrm{cd}}$ & $3.93 \pm 0.59^{c}$ & $5.07 \pm 0.69^{\mathrm{b}}$ & $5.57 \pm 0.87^{\mathrm{a}}$ \\
\hline \multirow{3}{*}{ Color } & $\mathrm{L}^{*}$ & $20.79 \pm 0.63^{\mathrm{a}}$ & $18.17 \pm 0.58^{b}$ & $17.57 \pm 0.40^{\mathrm{bc}}$ & $17.18 \pm 0.77^{\text {cd }}$ & $16.50 \pm 0.54^{\mathrm{d}}$ \\
\hline & $a^{*}$ & $-0.45 \pm 0.04^{\mathrm{d}}$ & $3.84 \pm 0.08^{c}$ & $4.63 \pm 0.13^{b}$ & $4.82 \pm 0.24^{\mathrm{ab}}$ & $4.95 \pm 0.34^{\mathrm{a}}$ \\
\hline & $b^{*}$ & $4.76 \pm 0.31^{\mathrm{c}}$ & $6.19 \pm 0.30^{b}$ & $6.21 \pm 0.43^{b}$ & $6.19 \pm 0.24^{\mathrm{b}}$ & $7.70 \pm 0.97^{\mathrm{a}}$ \\
\hline
\end{tabular}

${ }^{1)}$ Means within the same row without a common letter $(\mathrm{a}-\mathrm{e})$ are significantly different $(\mathrm{p}<0.05)$.

\section{Free radical scavenging activities}

Antioxidant activities were investigated based on DPPH radical scavenging activity and ABTS radical cation assay. The usage of $\mathrm{CC}$ in the jelly formulation enhanced levels of antioxidant activities (Fig. 2), which can be attributed to the abundant antioxidant capacities of CC. There were significant increases in electron donating ability (EDA) values of bound phenolic extracts in samples containing $\mathrm{CC}$ as compared to the control sample $(\mathrm{p}<0.05)$. EDA and ABTS values increased significantly with increasing amount of $\mathrm{CC}$ added $(\mathrm{p}<0.05)$. Sample enriched with $12 \% \mathrm{CC}$ showed the highest antioxidant potential. Data also showed a positive correlation between the antioxidant capacities of the various samples. EDA increased as ABTS increased.

\section{Sensory findings}

Color, flavor, taste, texture, and overall acceptance of control and CC-supplemented jellies were evaluated, and the

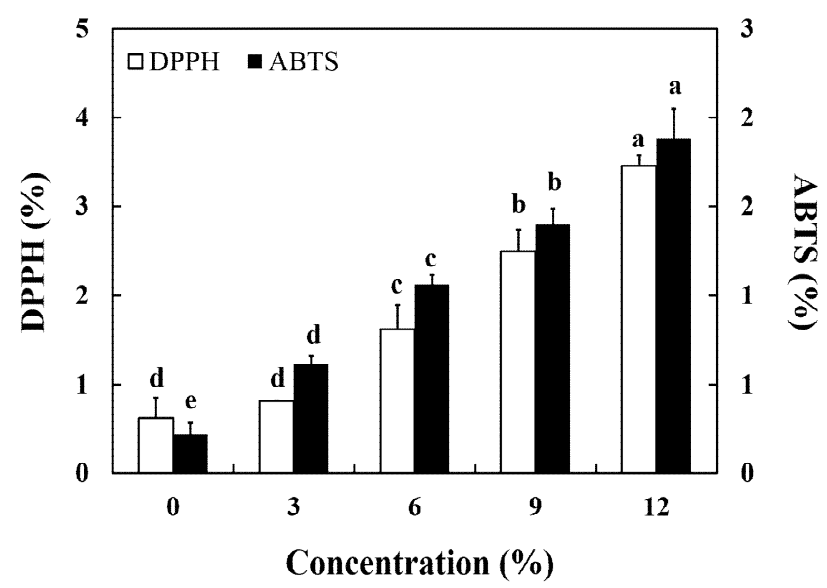

Fig. 2. DPPH and ABTS radical scavenging activities of jellies with different levels of corn concentrate.

Means within the same activity without a common letter are significantly different $(\mathrm{p}<0.05)$. results are presented as a radar plot (Fig. 3). When evaluated by untrained panelists, statistically significant differences in the attributes tested except for the flavor attribute were detected among samples $(\mathrm{p}<0.05)$. The sensory panelists rated the samples enriched with $6 \% \mathrm{CC}$ as having the highest scores for color, texture, taste, and overall acceptance as compared to other samples $(\mathrm{p}<0.05)$. However, further increasing substitution levels had undesirable sensorial effects. On a nine-point hedonic scale, $6 \% \mathrm{CC}$ sample received average scores in the range of 5.92-6.76, excluding the result for flavor since there was no significant difference among the samples ( $p>0.05$ ). Considering the $6 \% \mathrm{CC}$ sample received the highest overall acceptance score (6.40), partial replacement of $6 \%$ $\mathrm{CC}$ in the jelly formulation seems satisfactory. Similarly, in a study reported by Lee and Ji (10), 6\% partial replacement of cranberry concentrate was recommended in the jelly formulation without negatively affecting physical and sensory quality.

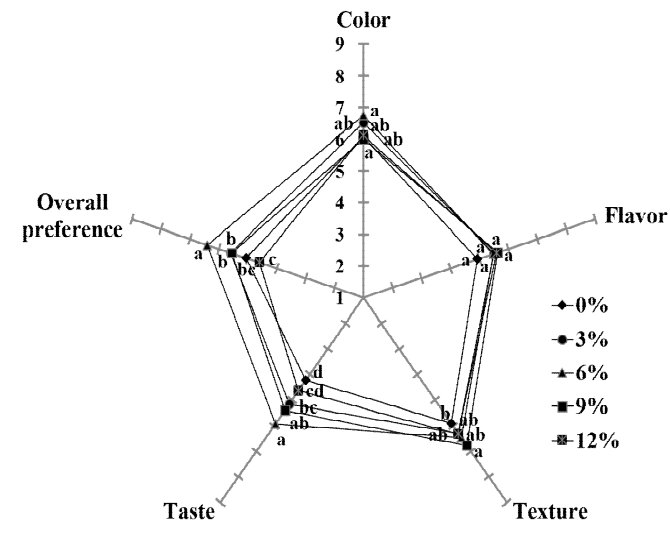

Fig. 3. Radar plot of sensory results of jellies with different levels of corn concentrate.

Means within the same attribute without a common letter are significantly different $(\mathrm{p}<0.05)$. 
Domestic and international corn markets have been in the spotlight for new renewable energy sources such as bioethanol, but demand for eco-friendly resources is needed to reduce the ratio of simple food and develop technologies in new processing areas. Korea has been a major importer of corn and we should consider better and alternative ways to consume other than eating itself. By taking advantage of the functional properties of $\mathrm{CC}$, it would be a good way to increase overall consumption of corn as well as its processed products such as $\mathrm{CC}$.

In addition, demand for convenient foods such as jelly is rising steadily and if $\mathrm{CC}$ is added as a value-added food ingredient to make jelly, it will improve overall quality of jelly. Based on our study, jelly with $6 \% \mathrm{CC}$ is recommended for developing $\mathrm{CC}$-added jellies with improved overall qualities without sacrificing consumer acceptability.

\section{References}

1. Burey P, Bhandari BR, Rutgers RPG, Halley PJ, Torley PJ (2009) Confectionery gels: A review on formulation, rheological and structural aspects. Int J Food Prop, 12, 176-210

2. Delgado P, Banon S (2017) Effects of replacing starch by inulin on the physicochemical, texture and sensory characteristics of gummy jellies. CyTA-J Food, 16, 1-10

3. Cho DH, Kim MJ, Sim EY, Jeon YH, Lee CK, Woo KS (2018) Effect of carbohydrase treatments on phenolics content and antioxidant activity of maize flour. Korean J Food Sci Technol, 50, 132-137
4. Kim AJ, Lim HJ, Kang SJ (2010) Quality characteristics of black ginseng jelly. Korean J Food Nutr, 23, 196-202

5. Lee JY, Yoon HY, Kim MR (2010) Quality characteristics of jelly with black garlic. Korean J Food Culture, 25, 832-838

6. Moon JN, Lee SW, Moon HK, Yoon SJ, Lee WY, Lee S, Kim GY (2011) Quality characteristics of chunma (Gastrodia elata Blume) jelly with added Gastrodia elata Blume concentrate. Korean J Food Cookery Sci, 27, 545-556

7. Kim NY, Jang KJ, Yang KH, Lee KJ, Kim MR (2011) Antioxidant activities and quality characteristics of jelly added Rehmannia radix Preparata concentrate. J East Asian Soc Diet Life, 21, 814-822

8. Choi EJ, Lee JH (2013) Quality and antioxidant properties of jelly incorporated with purple sweet potato concentrate. Korean J Food Sci Technol, 45, 47-52

9. Choi JE, Lee JH (2014) Quality and antioxidant property of gelatin jelly incorporated with jujube concentrate. Food Eng Prog, 18, 65-69

10. Lee JH, Ji YJ (2015) Quality and antioxidant properties of gelatin jelly incorporated with cranberry concentrate. J Korean Soc Food Sci Nutr, 44, 1100-1103

11. Brand-Williams W, Cuvelier ME, Berset C (1995) Use of a free radical method to evaluate antioxidant activity. LWT-Food Sci Technol, 28, 25-30

12. Re R, Pellegrini N, Proteggente A, Pannala A, Yang M, Rice-Evans C (1999) Antioxidant activity applying an improved ABTS radical cation decolorization assay. Free Radical Biol Med, 26, 1231-1237 